8 Muth, R. G., Annals of Internal Medicine, 1968, 69, 249

9 Wertheimer, L., et al., Archives of Internal Medicine, 1971, 127, 934

10 Anderson, J., et al., Quarterly fournal of Medicine, 1971, 40, 541.

11 Toivonen, S., and Mustala, O., British Medical fournal, 1966, 1, 920.

${ }^{12}$ Mustala, O., and Toivonen, S., Lancet, 1967, 1, 901.

13 Hicks, B. H., et al., Metabolism, 1973, 22, 101.

14 Walsh, C. H., and O'Sullivan, D. J., fournal of the Irish Medical Association, 1974, 67, 187.

15 Lavender, S., and McGill, R. J., Diabetes, 1974, 23, 247.

16 Alberti, K. G. M. M., and Hockaday, T. D. R., Postgraduate Medical Fournal, 1973, 49, 29.

17 Srivastava, R. N., et al., Fournal of Pediatrics, 1969, 74, 126.

18 Committee on Safety of Medicines. Personal communication, 1974.

\section{Antituberculous Drugs and the Liver}

The clinician is faced with a difficult problem of management when a patient receiving drugs develops signs of hepatic damage. He cannot always be certain that the reaction is due to the therapeutic agent rather than to a coincidental viral hepatitis or some other unrelated cause, but he is reluctant to continue treatment with the risk of precipitating severe hepatic necrosis. Probably the commonest clinical situation in which this arises is in patients being treated with antituberculous drugs, for many of these compounds (with the notable exception ${ }^{1}$ of streptomycin) appear to be prone to produce liver damage. The broad spectrum of hepatic dysfunction ranges from slight rises of serum aspartate aminotransferase (SGOT) in otherwise asymptomatic patients to severe hepatocellular necrosis. An asymptomatic rise in the SGOT has been shown to occur in $10-20 \%$ of patients given chemoprophylaxis with isoniazid. ${ }^{2}$ In contrast, clinically overt hepatitis with jaundice is much less common in patients taking this drug, with an estimated incidence ${ }^{4}$ of about $0.1 \%$. Fatal cases are even rarer, though they tend to be remembered more.

Hypersensitivity reactions to para-aminosalicylic acid (PAS) causing fever, rashes, and lymphadenopathy occur in up to $5 \%$ of patients on the drug, ${ }^{5}$ and in $40 \%$ of these cases the SGOT becomes raised. ${ }^{6}$ If the drug is not withdrawn at an early stage in the reaction a florid hepatitis may occur, which has a reported ${ }^{5}$ mortality of $21 \%$. However, isoniazid and PAS are commonly used together in the treatment of tuberculosis, and it is often difficult to decide which, if either, of the two drugs is to blame. Similarly, pyrizinamide and ethionamide are almost invariably used in combination with other antituberculous agents, which makes the $5-10 \%$ incidence $^{7}$ of overt and subclinical hepatitis reported for both of these drugs very difficult to interpret. Similar problems exist in the interpretation of the $20 \%$ reported incidence of asymptomatic raised SGOT levels ${ }^{8}$ and $8 \%$ incidence of jaundice ${ }^{9}$ in patients receiving rifampicin, since this drug is very frequently given with isoniazid.

Certain clinical features may help to distinguish hepatic damage due to antituberculous drugs from a viral hepatitis, and these have been highlighted in a recent study by Rossouw and Saunders. ${ }^{10}$ In a retrospective analysis of 7492 patients they found that 35 developed hepatitis which could reasonably be attributed to antituberculous drugs. PAS was implicated in 16 cases, PAS or isoniazid in a further 12, isoniazid alone in three, and ethionamide in one. In four other cases multiple drugs were thought to be implicated. The overall mortality was $17 \%$, to which all drugs contributed equally with the exception of PAS, where no deaths occurred. All reactions became apparent within the first three months of starting treatment-in agreement with other reports-though there are a few well-documented cases in which hepatic damage occurred at four and five months. ${ }^{11}$ Most cases, and especially those associated with PAS, were preceded by prodromal symptoms with gastrointestinal disturbances and features suggestive of a generalized hypersensitivity reaction, such as rashes and arthralgia. Lymphadenopathy occurred in $40 \%$ of cases attributed to PAS, and in many cases eosinophilia and atypical mononuclear cells were common haematological findings. These, together with other allergic manifestations, helped to differentiate the illness from viral hepatitis in nearly $90 \%$ of cases. In contrast, such allergic manifestations have been less commonly associated with hepatitis ascribed to ethionamide, ${ }^{12}$ pyrizinamide, ${ }^{7}$ and rifampicin, ${ }^{9}$ and the clinical features of cases occurring with isoniazid have often been indistinguishable from those of viral hepatitis. ${ }^{11} 1314$ Histological appearances on liver biopsy can never provide conclusive proof of a drug-induced lesion, but features such as eosinophilic infiltration, granulomata, and fat deposition (if the patient is not a heavy drinker) are all suspicious pointers. ${ }^{15}$

Certain combinations of antituberculous drugs may be especially likely to lead to hepatic necrosis. In Rossouw and Saunders's paper $^{10}$ hepatitis was generally more severe in patients receiving PAS and isoniazid than in those on PAS alone. In another study ${ }^{16}$ disturbed hepatic function occurred in $35 \%$ of patients taking rifampicin and isoniazid-an incidence more than three times higher than in those on rifampicin and ethambutol.

One way of pinpointing the cause of hepatic damage is by way of a diagnostic challenge. ${ }^{10}$ Patients should be observed closely from the start of therapy and all drugs stopped immediately should symptoms suggestive of hypersensitivity or hepatic damage occur. After the reaction has settled a small single test dose of one of the agents may be given and liver function tests monitored over the ensuing week. If no abnormalities are observed a full therapeutic dose of the drug is then given for a further week with continued monitoring of liver function tests. The procedure is then repeated in turn for each of the antituberculous agents under suspicion, since sensitization may occur to more than one drug. ${ }^{4}$ Once the offending agent has been identified desensitization may be attempted with multiple small doses of the drug. ${ }^{45}$

If the patient's tuberculosis is so severe that a break in therapy is considered unjustified on no account should the same drugs be continued, for the risk of precipitating fatal hepatic necrosis is high, and corticosteroids provide little protection. ${ }^{17}$ In this situation the use of drugs such as ethambutol, cycloserine, and capreomycin, which have little propensity to cause hepatic damage, ${ }^{718}$ may be considered. Cross-sensitivity may occur between drugs which are chemically related, as are isoniazid, pyrizinamide and ethionamide,,$^{1920}$ and all these agents should be avoided if a reaction occurs to one of them.

Routine monitoring of SGOT levels in the early months of antituberculous therapy has been advocated to provide early warning of adverse reactions, and there is evidence that by such screening the development of severe hepatic damage from pyrizinamide may be prevented. ${ }^{21}$ However, this is difficult to carry out on a large scale, and even if performed at weekly intervals may not provide adequate warning of a rapidly developing hepatitis. The situation is further complicated by the fact that mild rises in SGOT in asymptomatic patients taking isoniazid ${ }^{2} 3$ and rifampicin ${ }^{22}$ may be selflimiting, which poses the problem of whether these drugs should be stopped in patients showing such abnormalities. In such monitoring schedules, blood samples should be taken before the morning dose when drug levels are lowest because 
PAS $^{23}$ and possibly also isoniazid ${ }^{24}$ can interfere with the estimation of SGOT to produce spuriously high values.

Some means of predicting a patient's hypersensitivity to antituberculous drugs is urgently needed. Unfortunately, in vitro tests such as the lymphocyte transformation test, in which the patient's lymphocytes are exposed to the drug under suspicion, have yielded conflicting results for antituberculous agents. ${ }^{25-28}$

1 Sherlock, S., in Drug Induced Diseases, 1972, 4, 241.

2 Smith, J. P., and Sharer, L., Annals of Internal Medicine, 1972, 71, 1113.

${ }^{3}$ Byrd, R. B., Nelson, R., and Elliot, R. C., Fournal of the American Medical Association, 1972, 220, 1471.

4 Bate, S. J., Di Mase, J. D., and Christianson, C. S., American Review of Respiratory Diseases, 1964, 90, 598.

5 Simpson, D. G., and Walker, J. H., American fournal of Medicine, 1960, 29, 297.

6 Smith, J. M., and Springett, V. H., Tubercle, 1966, 47, 245.

7 Citron, K. M., in Side Effects of Drugs, ed. L. Meyler and A. Herxheimer. Amsterdam, Excerpta Medica, 1972, 7, 423.

${ }^{8}$ Smith, J., et al., Chest, 1972, 61, 587.

${ }^{9}$ Lees, A. W., Tubercle, 1970, 51, 217.

10 Rossouw, J. E., and Saunders, S. J., Quarterly fournal of Medicine, 1975, 44, 1.

11 Maddrey, W. C., and Boitnott, J. K., Annals of Internal Medicine, 1973, $79,1$.

12 Conn, H. V., Binder, H. J., and Orr, H. D., American Review of Respiratory Diseases, 1964, 90, 542.

13 Garibaldi, R. A., et al., American Review of Respiratory Diseases, 1972, 106, 357.

14 Moss, J. D., Lewis, J. E., and Knauer, C. M., American Review of Respiratory Diseases, 1972, 106, 849.

15 Lancet, 1974, 1, 854.

16 Lees, A. W., Allam, G. W., and Smith, J., Tubercle, 1971, 52, 182.

17 Research Committee of the Tuberculosis Society of Scotland, British Medical Fournal, 1957, 2, 1131.

18 Segarra, P. V., Lorain, V., and Sherman, D. S., Scandinavian fournal of Respiratory Diseases, 1968, 49, 202.

19 Phillips, S., and Tashman, H., American Review of Respiratory Diseases, 1963, 87, 896.

20 Weinstein, H. J., and Hallett, W. Y., American Review of Respiratory Diseases, 1962, 86, 576.

21 Perez, V., Schaffner, F., and Popper, H., in Progress in Liver Disease, ed. H. Popper and F. Schaffner. New York, 1972.

22 Lal, S., et al., British Medical fournal, 1972, 1, 148.

23 Hood, J., and Middleton, J. E., Tubercle, 1970, 57, 313.

24 Noble, J., New England Fournal of Medicine, 1971, 285, 687.

25 Assem, E. S. K., Ndoping, N., and Nicholson, H., Clinical and Experimental Immunology, 1969, 5, 439.

${ }^{26}$ Matthews, K. D., Pan, P. M., and Wells, J. A., fournal of Allergy, 1971, 47, 105.

${ }^{27}$ Dove, J. T., Chaparras, S. D., and Hedrick, S. R., American Review of Respiratory Diseases, 1972, 106, 485.

${ }^{28}$ Hollins, P. J., and Simmons, A. V., Tubercle, 1970, 51, 328.

\section{Adult Respiratory-Distress Syndrome}

The adult respiratory-distress syndrome can be defined as noncardiogenic pulmonary oedema occurring in patients with previously normal lungs. The conventional teaching is that pulmonary oedema occurs as a result of an imbalance of the normal hydrodynamic forces across the alveolar capillary membrane. This most often occurs as a consequence of left ventricular failure or left atrial hypertension leading to an increase in pulmonary venous pressure. ${ }^{1}$ However, it is now clear that pulmonary oedema can occur when the pulmonary venous pressure is not raised and where the lungs were previously normal. In most such patients there is damage to the alveolar-capillary membrane and increased pulmonary capillary endothelial permeability; there is invariably tissue hypoxia, hypotension, and respiratory or metabolic acidosis; and in some instances there are additional, more complex aetiological factors such as disseminated intravascular coagulation. ${ }^{5}$

Clinically the patient with the adult respiratory-distress syndrome is shocked, acutely dyspnoeic, and cyanosed and has diffuse alveolar exudates on the chest radiograph. Arterial blood gas analysis shows severe hypoxaemia $\left(\mathrm{PaO}_{2}\right.$ below $6.63 \mathrm{kPa}$ ) when breathing room air, a markedly widened alveolar-arterial oxygen gradient on supplemental oxygen, and sometimes hypercapnia. ${ }^{6}$ Conditions in which the syndrome occurs include blast injury to the lung, severe hypoxaemia after burns or extensive injury, septicaemia, endotoxaemia, renal failure, cerebral trauma, fat embolism, exposure to high altitudes, aspiration and viral pneumonias, drug overdose particularly with heroin and the barbiturates, and after cardiopulmonary bypass: and this list is not exhaustive. ${ }^{2-5}$

Whatever the precipitating cause of the condition, these patients are gravely ill and when admitted to hospital are usually soon transferred to an intensive care unit. Treatment should be directed towards improvement in oxygenation, artificial ventilation given where indicated, correction by suitable intravenous therapy of the acid-base disturbance and treatment of infection (when present) by appropriate antibiotics. However, the pathophysiological consequences of the adult respiratory-distress syndrome may lead to myocardial dysfunction and left ventricular failure, which must be recognized and treated, because when it is treated promptly the prognosis is improved. But how is the presence of left ventricular failure in the adult respiratory-distress syndrome recognized? Unger et $a l .{ }^{6}$ have recently claimed that physical examination is unreliable; they found that tachycardia, raised jugular venous pressure, cardiomegaly, hepatomegaly, and adventitious sounds in the lungs were equally common in patients with adult respiratory distress syndrome with or without left ventricular failure. Nor was the electrocardiograph helpful. Only the presence of peripheral oedema and a left ventricular third heart sound were slightly more common in those with left ventricular failure than in those without, but these signs of themselves were not diagnostic.

Of the tests done by Unger et al. the most useful in detecting left ventricular failure was measurement of the pulmonary wedge pressure. This we know is a good indicator of left ventricular end-diastolic pressure and thus of left ventricular failure. ${ }^{7}$ Of their 14 patients, 10 had a pulmonary wedge pressure below $12 \mathrm{~mm} \mathrm{Hg}$ (mean $5 \mathrm{~mm} \mathrm{Hg}$, range 2.0-9.5 $\mathrm{mm} \mathrm{Hg}$ ) and were therefore considered not to have left ventricular failure, whereas 4 patients had pressures above $12 \mathrm{~mm} \mathrm{Hg}$ (mean $20 \mathrm{~mm} \mathrm{Hg}$, range $15-23 \mathrm{~mm} \mathrm{Hg}$ ) and were considered to have left ventricular failure. In three of the four patients in the failure group a decrease in pulmonary wedge pressure was noted after fluid and salt restriction, diuretics, dialysis, or digitalis. All three had at the same time clinical improvement, a decrease in infiltrates on the chest film, and an increase in arterial oxygen tension. Three of these four patients survived, whereas of the 10 patients with the adult respiratory-distress syndrome without left ventricular failure only six survived. The four who died had necropsies; and two had normal hearts, one had evidence of an old healed myocardial infarct, and one had extensive acute bronchopneumonia and an agonal myocardial infarct (his pulmonary wedge pressure rose to abnormal levels terminally). Of the four with a raised pulmonary wedge pressure, the one who died had severe pneumonia and extensive, widespread fibrosis of the myocardium.

There are important lessons to be learnt from this experience, though the number of patients studied is small. Right heart catheterization is a simple, safe bedside procedure and 